\title{
Dexmedetomidine plus sufentanil for pediatric flexible bronchoscopy: A retrospective clinical trial
}

\author{
Xiujing Dang ${ }^{1, *}$, Weidong $\mathrm{Hu}^{1, *}$, Zhendong Yang ${ }^{1}$ and Shiyu Su${ }^{2}$ \\ ${ }^{1}$ Department of Anesthesiology, Qilu Children's Hospital of Shandong University, Jinan, Shandong, 250022, P.R. China \\ ${ }^{2}$ Department of Anesthesiology, The Fifth People's Hospital of Jinan, Jinan, Shandong, 250022, P.R. China \\ *These authors have contributed equally to this work \\ Correspondence to: Shiyu Su, email: 784253489@qq.com \\ Keywords: dexmedetomidine, sufentanil, pediatric, flexible bronchoscopy \\ Received: January 17, $2017 \quad$ Accepted: March 22, $2017 \quad$ Published: April 17, 2017 \\ Copyright: Dang et al. This is an open-access article distributed under the terms of the Creative Commons Attribution License 3.0 \\ (CC BY 3.0), which permits unrestricted use, distribution, and reproduction in any medium, provided the original author and source \\ are credited.
}

\section{ABSTRACT}

Several studies have reported the use of dexmedetomidine (DEX) plus opioids for flexible bronchoscopy in both adults and children. To determine whether DEX plus sufentanil (SF) is safe for children, 142 children undergoing flexible bronchoscopy were assigned to one of three groups, each of which received the same SF loading dose and similar DEX and SF maintenance doses, but different loading doses of DEX: DS1 (DEX $0.5 \mu \mathrm{g} \cdot \mathrm{kg}^{-1}$ ), DS2 (DEX $1.0 \mu \mathrm{g} \cdot \mathrm{kg}^{-1}$ ), and DS3 (DEX $1.5 \mu \mathrm{g} \cdot \mathrm{kg}^{-1}$ ). The Ramsay sedation scale was maintained at 3 in all groups. Results showed that anesthesia onset time was shorter, and the perioperative hemodynamic profile was more stable, in the DS3 group. The number of intraoperative movements was also lowest in the DS3 group. The time to first dose of rescue midazolam and lidocaine was significantly longer, but the total corresponding accumulated doses were lower in the DS3 group. Although the time to recovery prior to discharge from the post anesthesia care unit was longer, the overall incidence of tachycardia was lower in the DS3 group, and it received the highest bronchoscopist satisfaction score among the three groups. We therefore conclude that high-dose DEX plus SF can be safely and efficaciously used in children undergoing flexible bronchoscopy.

\section{INTRODUCTION}

Flexible bronchoscopy has been widely used since first implemented in 1968 [1]. When performed in pediatric patients, general anesthesia and monitored anesthesia care (MAC) are preferred, as they provide higher success rates $[2,3]$. However, flexible bronchoscopy represents a unique challenge for the anesthesiologist, as it requires maximizing both bronchoscopist and patient satisfaction [4]. Short acting opioids (fentanyl, remifentanil and sufentanil), newer drugs (dexmedetomidine), and modern ventilation technologies (supraglottic airways and mechanical jet ventilators) have facilitated the procedure. Nevertheless, medical teams are now opting for setting up a technical team with a dedicated anesthesiologist to deal with potentially increased adverse events [5-7].

Whereas general anesthesia is usually preferred for complex bronchoscopy, MAC ('conscious sedation' plus topical anesthesia) may be used for simple flexible bronchoscopy [8]. Benzodiazepines (midazolam), intravenous general anesthetics (propofol, etomidate, opioids), inhalational agents (sevoflurane, desflurane) or a combination of these drugs are commonly used during simple flexible bronchoscopy; however, each of these drugs has limitations $[8,9]$. Benzodiazepines and intravenous general anesthetics, except opioids, have no analgesic properties. Opioids (fentanyl, sufentanil, remifentanil) can provide excellent analgesia but have modest sedative effects. Inhalational agents have unavoidable defects such as causing air pollution. Most important of all, inadequate combinations of these drugs can result in severe respiratory depression, which is the most common complication of flexible bronchoscopy [10 12]. Thus, the need to optimize drug combinations during this procedure is critical, especially when it is performed in children. 
Dexmedetomidine (DEX), a highly selective $\alpha 2$ adrenergic receptor agonist, has a more favorable pharmacokinetic profile than clonidine [13]. Previous studies have reported that DEX, as compared with midazolam, propofol, fentanyl, and remifentanil, could be safely and effectively used for bronchoscopic procedures $[14,15]$. However, according to a search for English language articles published between 1995 and 2015 on MEDLINE, PubMed, EMBASE, Cochrane Central Register of Controlled Trials, and Web of Science that included the terms dexmedetomidine, sufentanil, pediatric, children, and flexible bronchoscopy, did not yield any studies reporting on the safety and efficacy of DEX plus SF in children undergoing flexible bronchoscopy. To address this evidence gap, we conducted the present retrospective trial.

\section{RESULTS}

\section{Baseline characteristics}

263 children undergoing flexible bronchoscopy were screened between January 2016 and October 2016 (Figure 1). 121 children were excluded: 13 who had congenital diseases, 5 who had second degree heart block, 32 with history of asthma, 13 with neuropsychiatric diseases, 40 in whom the operation time was shorter than $1 / 2 \mathrm{~h}, 6$ with a pulse oxygen saturation $<90 \%$ prior to the procedure, and 12 with a BMI $>30 \mathrm{~kg} \cdot \mathrm{m}^{-2}$. In total, 142 children were included in the study. They were divided into three groups (DS1, $\mathrm{n}=50 ; \mathrm{DS} 2, \mathrm{n}=44$; and DS3, $\mathrm{n}=48$ ). Demographic and baseline clinical parameters were not significantly different among the three groups (Table 1).

\section{Intraoperative variables}

Baseline hemodynamic measurements were similar among the three groups (Figure 2). Compared with the DS1 group, both heart rate (HR) and mean arterial pressure (MAP) were significantly decreased from T2 to T10 in the DS2 and DS3 groups $(P<0.05$, Figure 2$)$. Compared with the DS2 group, both HR and MAP were significantly decreased from T3 to T6 in the DS3 group $(P<0.05$, Figure 2).

Among the three groups, anesthesia onset time was significantly shorter in DS3 $(16.02 \pm 3.49$ vs $14.89 \pm 4.23$ vs $12.11 \pm 3.44 \mathrm{~min}, P<0.001$, Table 2$)$. Total dose of rescue midazolam was significantly higher in DS1 and DS2 than in DS3 $(1.45 \pm 0.47$ vs $1.22 \pm 0.43$ vs $1.02 \pm$ $0.34 \mathrm{mg} P<0.001$, Table 2, Figure 3), while total dose of rescue lidocaine was significantly lower in DS3 (6.35 \pm 2.09 vs $6.68 \pm 2.11$ vs $4.38 \pm 1.25 \mathrm{ml}, P<0.001$, Table 2, Figure 3$)$. Times to first dose of rescue midazolam $(9.36$ \pm 2.46 vs $11.82 \pm 3.23$ vs $13.80 \pm 3.13 \mathrm{~min}, P<0.001$, Table 2$)$ and lidocaine $(10.43 \pm 2.85 v s 12.41 \pm 2.98 v s$ $14.52 \pm 3.57 \mathrm{~min}, P<0.001$, Table 2 ) were significantly longer in DS3. Total cumulative dose of DEX was higher in DS3 (38.56 \pm 10.98 vs $46.25 \pm 16.42$ vs $55.47 \pm 14.22$ $\mu \mathrm{g}, P<0.001$, Table 2). Total cumulative dose of SF was higher in DS1 $(23.38 \pm 4.02$ vs $19.49 \pm 4.11$ vs $17.94 \pm$ $3.87 \mu \mathrm{g}, P<0.001$, Table 2).

The total number of movements during the bronchoscopy was lower in the DS3 group $(52.00 \%$ vs $40.91 \%$ vs $22.92 \%, P=0.012$, Table 2). Eight children from DS1, 6 children from DS2, and 5 children from DS3 required an alternative sedative (propofol) to complete

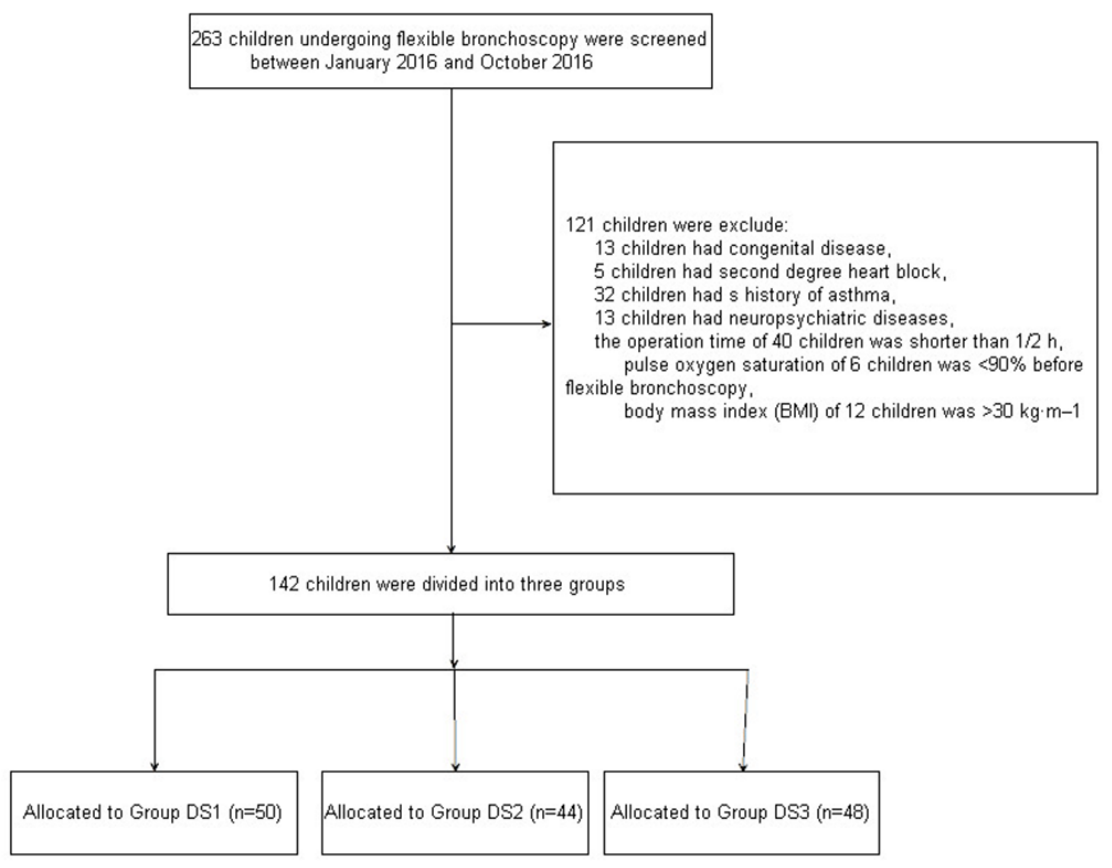

Figure 1: Patient enrollment flow diagram. 
Table 1: Demographic and baseline clinical parameters

\begin{tabular}{lcccc}
\hline Variable & $\begin{array}{c}\text { Group DS1 } \\
(\mathbf{n}=\mathbf{5 0})\end{array}$ & $\begin{array}{c}\text { Group DS2 } \\
(\mathbf{n}=\mathbf{4 4})\end{array}$ & $\begin{array}{c}\text { Group DS3 } \\
(\mathbf{n = 4 8})\end{array}$ & $\boldsymbol{P}$ \\
\hline Age $(\mathrm{y})$ & $9.54 \pm 2.84$ & $10.07 \pm 2.46$ & $9.34 \pm 2.74$ & 0.412 \\
Body weight $(\mathrm{kg})$ & $35.98 \pm 6.48$ & $34.51 \pm 7.82$ & $35.22 \pm 6.90$ & 0.602 \\
Sex (male/female) & $37 / 13$ & $30 / 14$ & $35 / 13$ & 0.805 \\
BMI $\left(\mathrm{kg} \cdot \mathrm{m}^{-2}\right)$ & $27.15 \pm 2.31$ & $27.48 \pm 3.05$ & $26.88 \pm 3.26$ & 0.611 \\
ASA (I/II) & $38 / 12$ & $35 / 9$ & $35 / 13$ & 0.758 \\
Duration of anesthesia (min) & $40.23 \pm 11.76$ & $43.15 \pm 12.03$ & $39.74 \pm 10.54$ & 0.311 \\
Duration of bronchoscopy (min) & $37.42 \pm 4.53$ & $39.16 \pm 5.44$ & $38.74 \pm 5.20$ & 0.217 \\
Type of bronchoscopy, n (\%) & & & & \\
$\quad$ Inspection & $35(70.00 \%)$ & $33(75.00 \%)$ & $32(66.67 \%)$ & 0.922 \\
Bronchoalveolar lavage & $8(16.00 \%)$ & $6(13.64 \%)$ & $8(16.67 \%)$ & \\
Transbronchial biopsy & $2(4.00 \%)$ & $3(6.82 \%)$ & $4(8.33 \%)$ & \\
Others & $5(10.00 \%)$ & $2(4.55 \%)$ & $4(8.33 \%)$ & \\
\hline
\end{tabular}

Variables presented as mean $\pm \mathrm{SD}$ or number of patients, $\mathrm{n}(\%)$. BMI=body mass index; ASA=American Society of Anesthesiology.

the procedure $(P=0.747$, Table 2$)$. There were significant differences among the three groups in terms of the overall incidence of tachycardia (46.00\% vs $38.64 \%$ vs $25.00 \%$, $P=0.042$, Table 3 ). However, there was no difference among groups in vasoactive drug usage (Table 4).

\section{Postoperative variables}

Recovery time before discharge from the post anesthesia care unit (PACU) (time to an Aldrete score $\geq 9$ ) was significantly longer in the DS3 group compared with the other two groups $(12.35 \pm 3.48 v s 13.78 \pm 3.82$ vs $15.35 \pm 4.02, P=0.001$, Table 5). Bronchoscopist satisfaction scores showed significant higher in DS3 than in DS1 and DS2 $(P=0.008$, Table 5).

\section{DISCUSSION}

Our results show that flexible bronchoscopy under the high DEX, DS3 protocol (i.e. DEX infusion at 1.5 $\mu \mathrm{g} \cdot \mathrm{kg}^{-1}$ for $10 \mathrm{~min}$, then adjusted to $0.5-0.7 \mu \mathrm{g} \cdot \mathrm{kg}^{-1} \cdot \mathrm{h}^{-1}$; SF infusion at $0.3 \mu \mathrm{g} \cdot \mathrm{kg}^{-1}$ for $10 \mathrm{~min}$, then adjusted to $0.1-0.3$ $\mu \mathrm{g} \cdot \mathrm{kg}^{-1} \cdot \mathrm{h}^{-1}$ ) shortened the anesthesia onset time, decreased the number of intraoperative patient movements and the overall incidence of tachycardia, and resulted in a more stable perioperative hemodynamic profile. Children in the DS3 group also needed a lower dose of rescue midazolam and lidocaine to complete the procedure, and the time to the first dose of rescue medication was also significantly longer in this group. For these children, however, the recovery time prior to discharge from the PACU was significantly longer than for those in the other two groups.

Rigid bronchoscopy is usually used for airway or esophageal foreign body removal in adults and children, while flexible bronchoscopy is usually used by respiratory physicians and pediatricians for the diagnosis and treatment of respiratory diseases [16, 17]. General anesthesia is still the gold standard technique for rigid bronchoscopy, and also for complex procedures where a flexible bronchoscope is used. In contrast, most flexible bronchoscopies can be done under topical anesthesia, MAC, or general anaesthesia [3]. MAC, i.e 'conscious sedation', has been recently used in many clinical fields, particularly in simple flexible bronchoscopy, as an alternative to topical anesthesia [18, 19]. Benzodiazepines have sedative, hypnotic, anxiolytic, anticonvulsant, and muscle relaxing effects and are one of the most commonly used sedatives during bronchoscopy. Because of its short elimination half-life and a fast onset of action, midazolam is a first-choice drug among the benzodiazepines. However, its pharmacological effects vary among patients, and it may depress the ventilatory drive and finally cause apnea, especially in patients with co-morbidities who are taking other respiratory depressant drugs [20, 21]. As a short-acting anesthetic agent with rapid recovery, propofol has been widely used in many clinical fields such as gastrointestinal endoscopy, thyroplasty, bronchoscopy, interventional or radiological procedures, and during awake bronchoscopy intubation, for its hypnotic effect $[22,23]$. Ketamine, on the other hand, has been 
increasingly used for flexible bronchoscopy in children for its sympatholytic and analgesic effects, as well as for its potent bronchodilator actions. However, it increases salivation and mucous secretions, and upper airway reflexes are preserved [24]. Though opioids are frequently used during bronchoscopy for its analgesic properties, they may lead to bradycardia, hypotension, and hypoxemia when in high doses or combined with other sedative drugs.
A usual solution for these problems, adopted recently by bronchoscopists and anesthesiologist, has been combining two or more agents $[14,25]$. As a mu opioid receptor, SF has short half-life and its analgesic potency is 5-10 times that of fentanyl. Previous studies have in fact reported the use of remifentanil in combination with propofol for flexible bronchoscopy in children [11]. DEX, a new selective $\alpha 2$-agonist, has sedative, anxiolytic and

HR
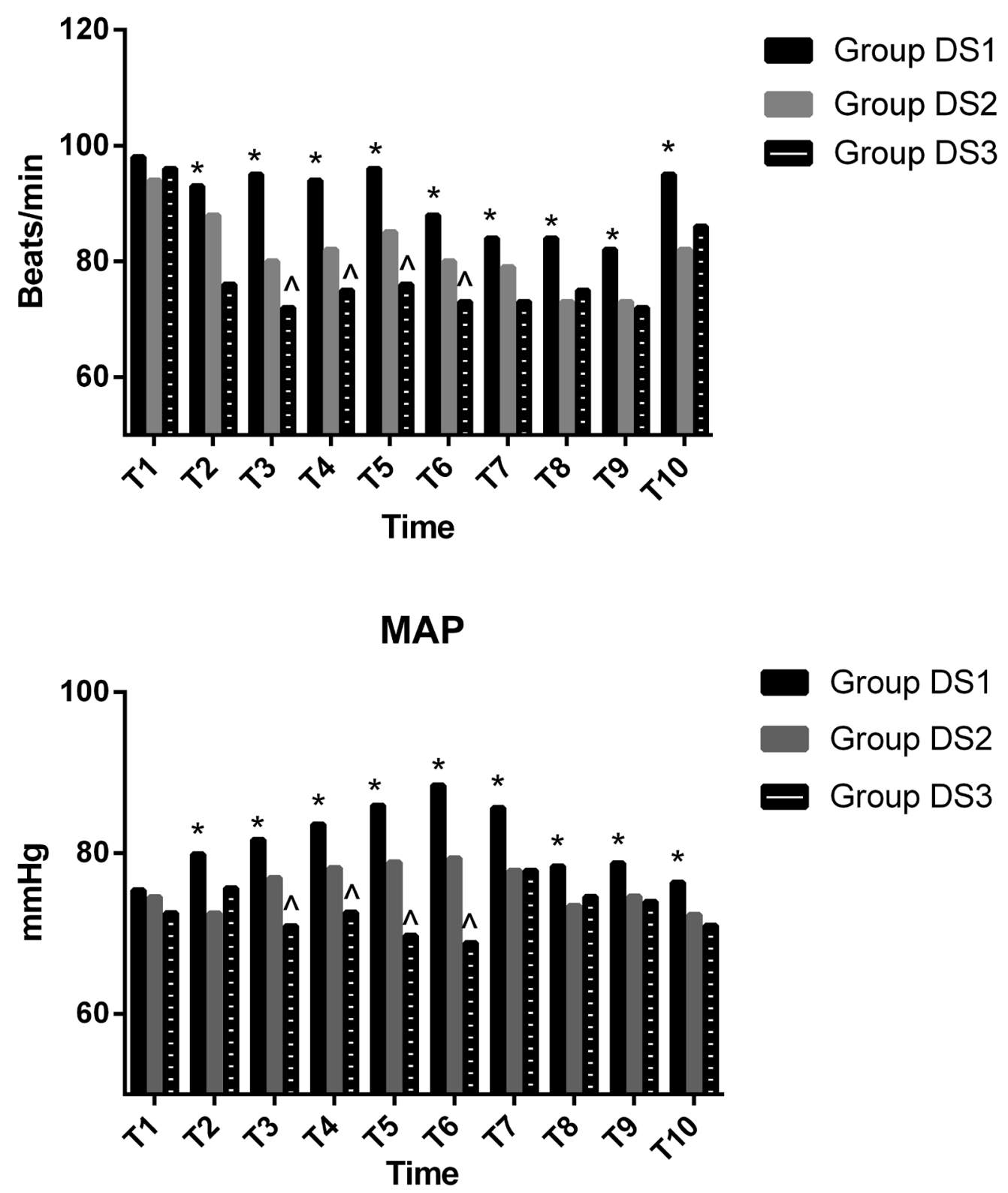

Figure 2: Hemodynamic measurements. Baseline hemodynamic values were similar among the three groups. Compared with the DS1 group, both HR and MAP were significantly decreased from T2 to T10 in the DS2 and DS3 groups $(P<0.05)$. Compared with the DS2 group, both HR and MAP were significantly decreased from T3 to T7 in the DS3 group $(P<0.05)$. T1, arrival at the operating room; T2, after bolus administration of drug; T3, at the initiation of flexible bronchoscopy; T4, 5 min after initiation of bronchoscopy; T5, 10 min after initiation of bronchoscopy; T6, at the end of bronchoscopy; T7, 5 min after arriving at PACU; T8, 10 min after arriving at PACU; T9, 20 min after arriving at PACU; T10, 30 min after arriving at PACU; $* P<0.05$ vs Group DS2 and Group DS3, ${ }^{\wedge} P<0.05$ vs Group DS2. 
Table 2: Intraoperative variables

\begin{tabular}{|c|c|c|c|c|}
\hline Variable & $\begin{array}{c}\text { Group DS1 } \\
(n=50)\end{array}$ & $\begin{array}{c}\text { Group DS2 } \\
(n=44)\end{array}$ & $\begin{array}{c}\text { Group DS3 } \\
(n=48)\end{array}$ & $\boldsymbol{P}$ \\
\hline Anesthesia onset time (min) & $16.02 \pm 3.49$ & $14.89 \pm 4.23$ & $12.11 \pm 3.44^{* \wedge}$ & 0.000 \\
\hline Time to first dose of rescue midazolam (min) & $9.36 \pm 2.46$ & $11.82 \pm 3.23 *$ & $13.80 \pm 3.13^{* \wedge}$ & 0.000 \\
\hline Time to first dose of rescue lidocaine ( $\mathrm{min}$ ) & $10.43 \pm 2.85$ & $12.41 \pm 2.98 *$ & $14.52 \pm 3.57^{* \wedge}$ & 0.000 \\
\hline Total dose of rescue midazolam (mg) & $1.45 \pm 0.47$ & $1.22 \pm 0.43 *$ & $1.02 \pm 0.34 * \wedge$ & 0.000 \\
\hline Total dose of rescue lidocaine $(\mathrm{ml})$ & $6.35 \pm 2.09$ & $6.68 \pm 2.11$ & $4.38 \pm 1.25^{* \wedge}$ & 0.000 \\
\hline Total dose of dexmedetomidine $(\mu \mathrm{g})$ & $38.56 \pm 10.98$ & $46.25 \pm 16.42 *$ & $55.47 \pm 14.22 * \wedge$ & 0.000 \\
\hline Total dose of sufentanil $(\mu \mathrm{g})$ & $23.38 \pm 4.02$ & $19.49 \pm 4.11 *$ & $17.94 \pm 3.87 *$ & 0.000 \\
\hline Total patient movements, $\mathrm{n}(\%)$ & $26(52.00 \%)$ & $18(40.91 \%)$ & $11(22.92 \%)^{*}$ & 0.012 \\
\hline converted to propofol, $\mathrm{n}(\%)$ & $8(16.00 \%)$ & $6(13.64 \%)$ & $5(10.42 \%)$ & 0.747 \\
\hline
\end{tabular}

Variables presented as mean $\pm \mathrm{SD}$ or number of patients, $\mathrm{n}(\%) .{ }^{*} P<0.05$ vs Group $\mathrm{DS} 1, \wedge P<0.05$ vs Group DS2.
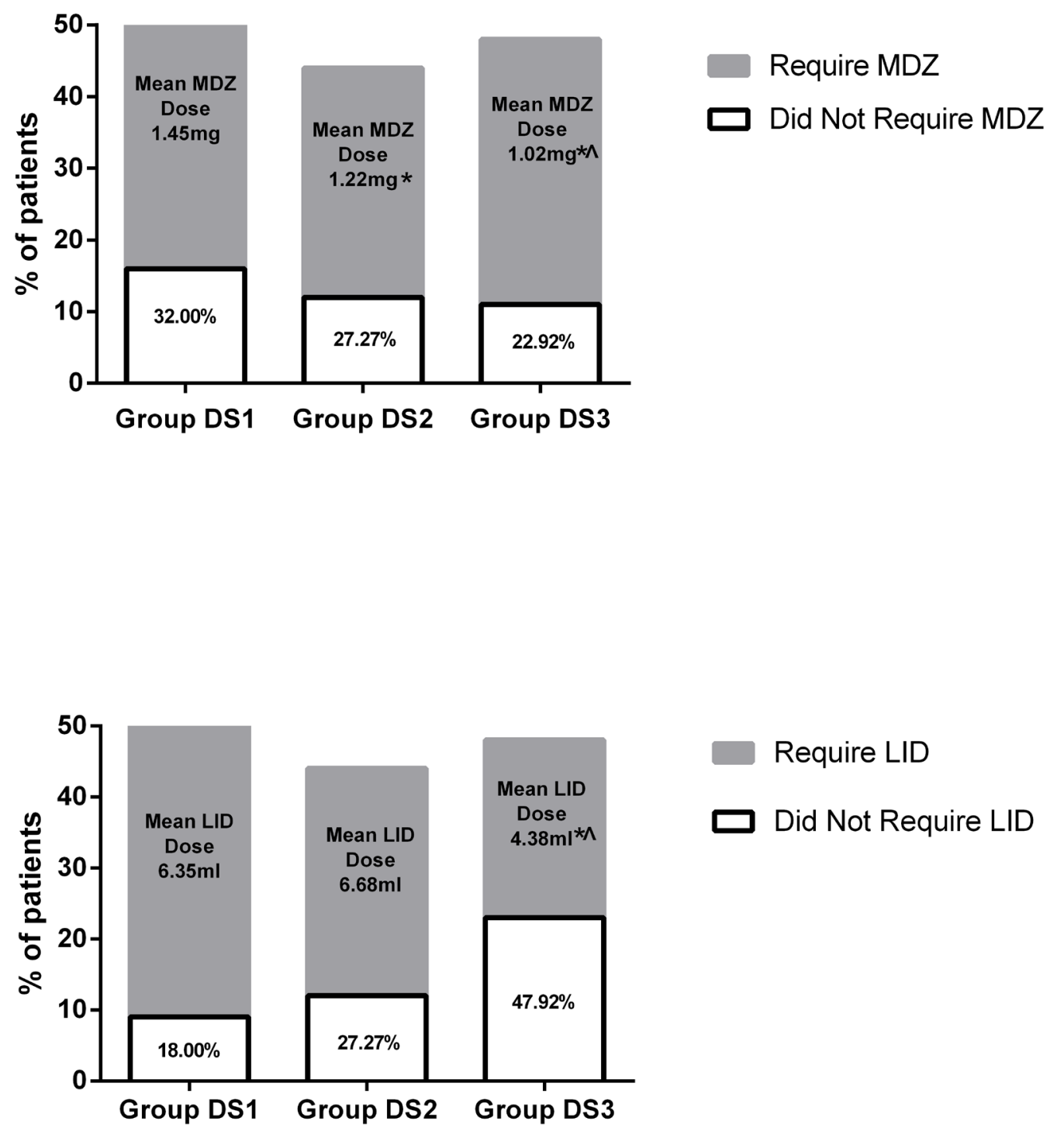

Figure 3: Midazolam and lidocaine use and dosage. $* P<0.05$ vs Group DS2 and Group DS3, ^ $P<0.05$ vs Group DS2. 
Table 3: Adverse events

\begin{tabular}{lcccc}
\hline Variable & $\begin{array}{c}\text { Group DS1 } \\
(\mathbf{n = 5 0 )}\end{array}$ & $\begin{array}{c}\text { Group DS2 } \\
(\mathbf{n = 4 4 )}\end{array}$ & Group DS3 (n=48) & $\boldsymbol{P}$ \\
\hline Tachycardia & $23(46.00 \%)$ & $17(38.64 \%)$ & $12(25.00 \%)$ & 0.042 \\
Hypertension & $20(40.00 \%)$ & $15(34.09 \%)$ & $11(22.92 \%)$ & 0.188 \\
Bradycardia & $7(14.00 \%)$ & $10(22.73 \%)$ & $12(25.00 \%)$ & 0.362 \\
Hypotension & $3(6.00 \%)$ & $6(13.64 \%)$ & $5(10.42 \%)$ & 0.468 \\
Nausea & $14(28.00 \%)$ & $12(27.27 \%)$ & $13(27.08 \%)$ & 0.994 \\
Vomiting & $4(8.00 \%)$ & $6(13.64 \%)$ & $5(10.42 \%)$ & 0.674 \\
Cough & $28(56.00 \%)$ & $22(50.00 \%)$ & $18(37.50 \%)$ & 0.176 \\
Hypoxemia & $16(32.00 \%)$ & $12(27.27 \%)$ & $8(16.67 \%)$ & 0.205 \\
\hline
\end{tabular}

Variables presented as number of patients, $\mathrm{n}(\%) .{ }^{*} P<0.05$ vs Group DS1, $\wedge P<0.05$ vs Group DS2.

Table 4: Vascular active drug usage during bronchoscopy

\begin{tabular}{lcccc}
\hline Variable & $\begin{array}{c}\text { Group DS1 } \\
(\mathbf{n = 5 0 )}\end{array}$ & Group DS2 (n=44) & Group DS3 (n=48) & $\boldsymbol{P}$ \\
\hline Urapidil & $16(32.00 \%)$ & $12(27.27 \%)$ & $8(16.67 \%)$ & 0.205 \\
Esmolol & $18(36.00 \%)$ & $13(29.55 \%)$ & $9(18.75 \%)$ & 0.166 \\
Ephedrine & $2(4.00 \%)$ & $5(11.36 \%)$ & $3(6.25 \%)$ & 0.384 \\
Atropine & $5(10.00 \%)$ & $8(18.18 \%)$ & $9(18.75 \%)$ & 0.399 \\
\hline
\end{tabular}

Variables presented as number of patients, n (\%).

Table 5: Postoperative variables

\begin{tabular}{lcccc}
\hline Variable & $\begin{array}{c}\text { Group DS1 } \\
(\mathbf{n = 5 0 )}\end{array}$ & $\begin{array}{c}\text { Group DS2 } \\
(\mathbf{n = 4 4 )}\end{array}$ & $\begin{array}{c}\text { Group DS3 } \\
(\mathbf{n = 4 8 )}\end{array}$ & $\boldsymbol{P}$ \\
\hline $\begin{array}{l}\text { Recovery time (min) } \\
\text { Bronchoscopist }\end{array}$ & $12.35 \pm 3.48$ & $13.78 \pm 3.82$ & $15.35 \pm 4.02 * \wedge$ & 0.001 \\
satisfaction score & $2.75(1.75-3.25)$ & $3.25(2.25-3.75)^{*}$ & $3.75(2.75-4.00)^{* \wedge}$ & 0.008 \\
\hline
\end{tabular}

Variables presented as mean $\pm \mathrm{SD}$ or median (interquartile range). ${ }^{*} P<0.05$ vs Group $\mathrm{DS} 1, \wedge P<0.05$ vs Group $\mathrm{DS} 2$.

analgesic effects. Furthermore, it has the advantage of causing mild respiratory depression, even at higher doses. Previous studies have reported that DEX can both decrease the incidence of desaturation and reduce tracheobronchial secretions [26]. A general recommendation is a DEX bolus infusion of $1 \mu \mathrm{g} \cdot \mathrm{kg}^{-1}$ for $10 \mathrm{~min}$, followed by maintenance infusion at a rate of $0.2-0.7 \mu \mathrm{g} \cdot \mathrm{kg}^{-1} \cdot \mathrm{h}^{-1}$, and SF infusion at $0.3 \mu \mathrm{g} \cdot \mathrm{kg}^{-1}$ for $10 \mathrm{~min}$, then adjusted to $0.1-0.3 \mu \mathrm{g} \cdot \mathrm{kg}^{-1} \cdot \mathrm{h}^{-1}$ for maintenance. However, as DEX has a larger apparent volume of distribution in children than in adults, children may need larger initial doses of DEX to reach comparable steady-state plasma levels, although the maintenance doses are similar [27]. Therefore, in this trial we adopted
DEX infusion at $0.5-1.5 \mu \mathrm{g} \cdot \mathrm{kg}^{-1}$ for $10 \mathrm{~min}$, then adjusted it to $0.5-0.7 \mu \mathrm{g} \cdot \mathrm{kg}^{-1} \cdot \mathrm{h}^{-1}$. Non-autonomous movements are one of the most common reasons of failure of flexible bronchoscopy in children. However, only a small number of children required conversion to propofol, due perhaps to the complementary drug effects in these studies.

Comparisons among the three groups revealed that anesthesia onset time was significantly shorter in the DS3 group. At the same time, fewer children in this group needed rescue drugs to complete the bronchoscopy, presumably as a result of better hemodynamic stability and the synergic sedative effects of DEX and SF at high doses. Though bradycardia and hypertension are the 
most common adverse reactions reported during bolus infusion of DEX, we did not observe differences in their incidence among the three groups, partly because they were counteracted by premedication in our study [11]. There were however significant differences among groups in the overall incidence of tachycardia (the lowest one observed in DS3) although vasoactive drug use was similar. The reasons for this may be ascribed to the different DEX and SF dosages used in the three groups. The overall time to recovery before discharge from the PACU was significantly shorter than reported previously [28]. However, compared with DS1 and DS2, recovery took longer for children in the DS3 group. On the other hand, bronchoscopist satisfaction scores were significantly higher in DS3, which may be due to the fewer intraoperative patient movements recorded for this group.

In summary, our results show that high dose of DEX-SF (DEX infusion at $1.5 \mu \mathrm{g} \cdot \mathrm{kg}^{-1}$ for $10 \mathrm{~min}$, then adjusted to $0.5-0.7 \mu \mathrm{g} \cdot \mathrm{kg}^{-1} \cdot \mathrm{h}^{-1}$; SF infusion at $0.3 \mu \mathrm{g} \cdot \mathrm{kg}^{-1}$ for $10 \mathrm{~min}$, then adjusted to $0.1-0.3 \mu \mathrm{g} \cdot \mathrm{kg}^{-1} \cdot \mathrm{h}^{-1}$ ), provided better and stable hemodynamic profiles, lower use of rescue medication, fewer intraoperative movements, and a higher bronchoscopist satisfaction score, although the recovery time was longer. We conclude that this sedation protocol could be safely and effectively used in children undergoing flexible bronchoscopy.

There are several limitations in this study. First, as it is a retrospective trial in a single medical center, a multicenter prospective controlled trial would be necessary to verify the superiority of high dosage DEX-SF in children undergoing flexible bronchoscopy. Second, due to technical limitations we did not measure patients' serum concentrations of DEX and SF. Third, we did not collect blood gas measurements or performed transcutaneous capnography, which may be more accurate to assess the respiratory state of our patients [28-30]. Finally, as we only discussed three different combinations of DEXSF, studies should be carried out to verify the efficacy of different doses of DEX-SF for pediatric flexible bronchoscopy.

\section{MATERIALS AND METHODS}

\section{Patients}

Approval for this retrospective clinical trial was obtained from the Institutional Review Board of Qilu Children's Hospital of Shandong University. Children undergoing flexible bronchoscopy between January 2016 and October 2016 were enrolled in this study after obtaining written informed consent of their parents if they met the following inclusion criteria: age between 7 and 12 years old, and American Society of Anesthesiology (ASA) grade I to II. Exclusion criteria included congenital disease, neuropsychiatric diseases, second or third degree heart block, asthma, operation time shorter than
$1 / 2 \mathrm{~h}$, pulse oxygen saturation $<90 \%$ before flexible bronchoscopy, and body mass index (BMI) $>30 \mathrm{~kg} / \mathrm{m}^{2}$.

Children were divided into three groups: DS1 $(n=50$, DEX infusion at $0.5 \mu \mathrm{g} \cdot \mathrm{kg}^{-1}$ for $10 \mathrm{~min}$, then adjusted to 0.5 $0.7 \mu \mathrm{g} \cdot \mathrm{kg}^{-1} \cdot \mathrm{h}^{-1}$; SF infusion at $0.3 \mu \mathrm{g} \cdot \mathrm{kg}^{-1}$ for $10 \mathrm{~min}$, then adjusted to $\left.0.1-0.3 \mu \mathrm{g} \cdot \mathrm{kg}^{-1} \cdot \mathrm{h}^{-1}\right)$, DS2 ( $\mathrm{n}=44$, DEX infusion at $1 \mu \mathrm{g} \cdot \mathrm{kg}^{-1}$ for $10 \mathrm{~min}$, then adjusted to $0.5-0.7 \mu \mathrm{g} \cdot \mathrm{kg}^{-}$ ${ }^{1} \cdot \mathrm{h}^{-1}$; SF infusion at $0.3 \mu \mathrm{g} \cdot \mathrm{kg}^{-1}$ for $10 \mathrm{~min}$, then adjusted to $\left.0.1-0.3 \mu \mathrm{g} \cdot \mathrm{kg}^{-1} \cdot \mathrm{h}^{-1}\right)$, and DS3 ( $\mathrm{n}=48$, DEX infusion at $1.5 \mu \mathrm{g} \cdot \mathrm{kg}^{-1}$ for $10 \mathrm{~min}$, then adjusted to $0.5-0.7 \mu \mathrm{g} \cdot \mathrm{kg}$ ${ }^{1} \cdot \mathrm{h}^{-1}$; SF infusion at $0.3 \mu \mathrm{g} \cdot \mathrm{kg}^{-1}$ for $10 \mathrm{~min}$, then adjusted to $\left.0.1-0.3 \mu \mathrm{g} \cdot \mathrm{kg}^{-1} \cdot \mathrm{h}^{-1}\right)$. All children and their parents were explained about the operative procedure on the day before surgery. Flexible bronchoscopy was performed by the same bronchoscopist, who has completed ten years of residency.

Children were fasted for 6 hours for solids and for 2 hours for clear fluids before the procedure [31]. After baseline hemodynamics were recorded, midazolam $0.03 \mathrm{mg} \cdot \mathrm{kg}^{-1}$ and atropine $0.01 \mathrm{mg} \cdot \mathrm{kg}^{-1}$ were given intravenously in the operating room [8]. Five-lead electrocardiography, noninvasive arterial blood pressure, peripheral pulse-oximetry $\left(\mathrm{SpO}_{2}\right)$, respiratory rate $(\mathrm{RR})$, and temperature (TEM) were continuously monitored using an automated system (Philips IntelliVue MP70). A forced-air warming device (EQUATOR Convective Warmer, EQ-5000) was used during the procedure to maintain normothermia.

\section{Flexible bronchoscopy}

After children received oxygen supplementation at $4 \mathrm{~L} \cdot \mathrm{min}^{-1}$ through a nasal cannula, loading doses of both DEX and SF were infused for $10 \mathrm{~min}$, followed by continuous drug maintenance infusion; topical anesthesia was then performed using $2 \mathrm{ml}$ of $1 \%$ lidocaine spray applied twice into the oral cavity. Upon visualization of the vocal cords, trachea, and the right and left main bronchi, $4 \mathrm{ml}$ of $1 \%$ lidocaine were delivered through the flexible bronchoscope channel to suppress the cough reflex. Once the Ramsay sedation score reached 3 (children still responding to commands), flexible bronchoscopy was performed [32]. Whenever indications of insufficient sedation were observed during the procedure, a rescue bolus of midazolam $0.03 \mathrm{mg} \cdot \mathrm{kg}^{-1}$ was given, repeated every $5 \mathrm{~min}$ to a maximum dose of $1.5 \mathrm{mg}$. Whenever indications of inadequate analgesia were observed during the procedure, an additional $2 \mathrm{ml}$ of $1 \%$ lidocaine was administered through the side hole of the flexible bronchoscope to a maximum dose of $10 \mathrm{ml}$. The amount of midazolam and lidocaine administered was recorded. If the patient did not reach an optimal sedation status after the maximum dose of midazolam and lidocaine, propofol $1.5 \mathrm{mg} \cdot \mathrm{kg}^{-1}$ was provided. DEX and SF infusion were stopped $5 \mathrm{~min}$ before the end of the procedure, after which all children received tropisetron $0.1 \mathrm{mg} \cdot \mathrm{kg}^{-1}$ before being transferred to the PACU. 
On arrival at the PACU, children were continuously monitored by five-lead electrocardiography, noninvasive arterial blood pressure and $\mathrm{SpO}_{2}$ for at least $12 \mathrm{~h}$. Hemodynamics [HR, noninvasive blood pressure, $\mathrm{SpO}_{2}$, TEM] were monitored every $5 \mathrm{~min}$ for the first $20 \mathrm{~min}$, then every $10 \mathrm{~min}$ until children were discharged (Aldrete Score $\geq 9$ ) [33]. Bronchoscopist satisfaction was assessed 24h after bronchoscopy [34].

\section{Adverse events}

Bradycardia and tachycardia were defined as a $\geq 30 \%$ reduction or increase of baseline $\mathrm{HR}$, and treated with intravenous atropine $0.01 \mathrm{mg} \cdot \mathrm{kg}^{-1}$ or esmolol 0.3 $\mathrm{mg} \cdot \mathrm{kg}^{-1}$, respectively. Hypertension and hypotension were defined as a $\geq 30 \%$ increase or decrease from baseline mean arterial blood pressure, and treated with intravenous urapidil $0.02 \mathrm{mg} \cdot \mathrm{kg}^{-1}$ or ephedrine $0.01 \mathrm{mg} \cdot \mathrm{kg}^{-1}$, respectively. Hypoxemia was defined as an $\mathrm{SpO}_{2}<90 \%$ for $>30 \mathrm{~s}$, and treated with oxygen supplementation at 6 $\mathrm{L} \cdot \mathrm{min}^{-1}$ or with verbal and tactile stimulation, chin lifts, jaw thrusts, a face mask, and manual ventilation [35].

\section{Outcome variables}

Intraoperative hemodynamic parameters (HR, noninvasive blood pressure, $\mathrm{SpO}_{2}$, TEM) were recorded at the following time points: upon arrival at the operating room (T1), after bolus administration of drugs (T2), at the initiation of flexible bronchoscopy (T3), 5 min after initiation of bronchoscopy (T4), $10 \mathrm{~min}$ after initiation of bronchoscopy (T5), at the end of bronchoscopy (T6) and $5 \mathrm{~min}$ (T7), $10 \mathrm{~min}$ (T8), $20 \mathrm{~min}$ (T9), and $30 \mathrm{~min}$ (T10) after being transferred to the PACU. Anesthesia onset time, the number of intraoperative movements, total cumulative doses of dexmedetomidine, sufentanil, midazolam, and lidocaine, time to first dose of rescue midazolam and lidocaine, postoperative recovery time, adverse events, and bronchoscopist satisfaction score were also recorded.

\section{Statistical analysis}

The Kolmogorov-Smirnov test was used to assess the distribution of variables. Homogeneity of variances was determined using Levene's tests. Quantitative data was expressed as mean and standard deviation or median and inter-quartile range (IQR). Inter-group comparisons were performed using repeated-measures analysis of variance. The Bonferroni's correction was used for posthoc multiple comparisons. The nonparametric KruskalWallis test was used for variables that were not normally distributed. Categorical data was expressed as frequency and percentage and analyzed using chi-squared tests or Fisher's exact tests when appropriate. $P<0.05$ was considered statistically significant. Statistical analysis was performed with SPSS for Windows version 18.0 (SPSS Inc. Chicago, IL, USA).

\section{Abbreviations}

DEX: dexmedetomidine; SF: sufentanil; MAC: monitored anesthesia care; HR: heart rate; MAP: mean arterial pressure; PACU: post anesthesia care unit; BMI: body mass index; ASA: American Society of Anesthesiology; $\mathrm{SpO}_{2}$ : pulse-oximetry; RR: respiratory rate: TEM: temperature; IQR: inter-quartile range.

\section{Author contributions}

Xiujing Dang and Shiyu Su conceived and designed the trail; Zhendong Yang analyzed the data; Weidong $\mathrm{Hu}$ collected the data; Xiujing Dang, Weidong Hu and Shiyu $\mathrm{Su}$ wrote the article.

\section{CONFLICTS OF INTEREST}

The authors declared that the research was conducted in the absence of any commercial or financial relationships that could be construed as a potential conflict of interest.

\section{FUNDING}

None.

\section{REFERENCES}

1. Casal RF, Ost DE, Eapen GA. Flexible bronchoscopy. Clin Chest Med. 2013; 34:341-352.

2. Goudra BG, Singh PM, Borle A, Farid N, Harris K. Anesthesia for Advanced Bronchoscopic Procedures: Stateof-the-Art Review. Lung. 2015;193:453-465.

3. Ausseur A, Chalons N. Anesthesia in interventional bronchoscopy. Rev Mal Respir. 1999;16:679-683.

4. Wahidi MM, Jain P, Jantz M, Lee P, Mackensen GB, Barbour SY, Lamb C, Silvestri GA. American College of Chest Physicians consensus statement on the use of topical anesthesia, analgesia, and sedation during flexible bronchoscopy in adult patients. Chest. 2011;140:1342-1350.

5. Dhooria S, Sehgal IS, Aggarwal AN, Behera D, Agarwal R. Diagnostic Yield and Safety of Cryoprobe Transbronchial Lung Biopsy in Diffuse Parenchymal Lung Diseases: Systematic Review and Meta-Analysis. Respir Care. 2016;61:700-712.

6. José RJ, Shaefi S, Navani N. Anesthesia for bronchoscopy. Curr Opin Anaesthesiol. 2014;27:453-457.

7. Garnock-Jones KP, Scott LJ. Fospropofol. Drugs. 2010;70:469-477.

8. Chadha M, Kulshrestha M, Biyani A. Anaesthesia for bronchoscopy. Indian J Anaesth. 2015;59:565-573.

9. Abdelmalak B, Khanna A, Tetzlaff J. Fospropofol, a new sedative anesthetic, and its utility in the perioperative period. Curr Pharm Des. 2012;18:6241-6252. 
10. Geraci G, Pisello F, Sciumè C, Li Volsi F, Romeo M, Modica G. [Complication of flexible fiberoptic bronchoscopy]. [Article in Italian]. Ann Ital Chir. 2007; 78:183-192.

11. Bauer TL, Berkheim DB. Bronchoscopy: Diagnostic and Therapeutic for Non-Small Cell Lung Cancer. Surg Oncol Clin N Am. 2016;25:481-491.

12. Poletti V1, Casoni GL, Gurioli C, Ryu JH, Tomassetti S. Lung cryobiopsies: a paradigm shift in diagnostic bronchoscopy? Respirology. 2014;19:645-654.

13. Pan W, Wang Y, Lin L, Zhou G, Hua X, Mo L. Outcomes of ddexmedetomidine treatment in pediatric patients undergoing congenital heart disease surgery: a metaanalysis. Paediatr Anaesth. 2016;26:239-248.

14. Liao W, Ma G, Su QG, Fang Y, Gu BC, Zou XM. Dexmedetomidine versus midazolam for conscious sedation in postoperative patients undergoing flexible bronchoscopy: a randomized study. J Int Med Res. 2012;40:1371-1380.

15. Ryu JH, Lee SW, Lee JH, Lee EH, Do SH, Kim CS. Randomized double-blind study of remifentanil and dexmedetomidine for flexible bronchoscopy. Br J Anaesth. 2012;108:503-511.

16. Hong KS, Choi EY, Park DA, Park J. Safety and Efficacy of the Moderate Sedation During Flexible Bronchoscopic Procedure: A Systematic Review and Meta-Analysis of Randomized Controlled Trials. Medicine (Baltimore). 2015;94:e1459.

17. Zhou GW, Zhang W, Dong YC, Huang HD, Hu C, Sun J, Jin F, Gu Y, Li Q, Li S. Flexible bronchoscopy-induced massive bleeding: A 12-year multicentre retrospective cohort study. Respirology. 2016;21:927-931.

18. Fuehner T, Fuge J, Jungen M, Buck A, Suhling H, Welte T, Gottlieb J, Greer M. Topical Nasal Anesthesia in Flexible Bronchoscopy-A Cross-Over Comparison between Two Devices. PLoS One. 2016;11:e0150905.

19. von Ungern-Sternberg BS, Trachsel D, Zhang G, Erb TO, Hammer J. Topical Lidocaine Does Not Exaggerate Laryngomalacia in Infants During Flexible Bronchoscopy Under Propofol Anesthesia. J Bronchology Interv Pulmonol. 2016; 23:215-219.

20. Contoli M, Gnesini G, Artioli D, Ravenna C, Sferra S, Romanazzi C, Marangoni E, Guzzinati I, Pasquini C, Papi A, Ravenna F. Midazolam in flexible bronchoscopy premedication: effects on patient-related and procedurerelated outcomes. J Bronchology Interv Pulmonol. 2013;20:232-240.

21. Rolo R, Mota PC, Coelho F, Alves D, Fernandes G, Cunha J, Hespanhol V, Magalhães A. Sedation with midazolam in flexible bronchoscopy: a prospective study. Rev Port Pneumol. 2012;18:226-232.

22. Wang $H$, Yang C, Zhang B, Xia Y, Liu H, Liang H. Efficacy of target-controlled infusion of propofol and remifentanil with high frequency jet ventilation in fibreoptic bronchoscopy. Singapore Med J. 2013;54:689-694.
23. Grendelmeier P, Tamm M, Pflimlin E, Stolz D. Propofol sedation for flexible bronchoscopy: a randomised, noninferiority trial. Eur Respir J. 2014;43:591-601.

24. Strayer RJ, Nelson LS. Adverse events associated with ketamine for procedural sedation in adults. Am J Emerg Med. 2008;26:985-1028.

25. Ozturk T, Acikel A, Yilmaz O. Effects of low-dose propofol vs ketamine on emergence cough in children undergoing flexible bronchoscopy with sevoflurane-remifentanil anesthesia: a randomized, double-blind, placebo-controlled trial. J Clin Anesth. 2016;35:90-95.

26. Nakanishi R, Yoshimura M, Suno M, Yamamoto K, Ito H, Uchimine Y, Toriumi T, Kurosawa A, Sugawara A, Kunisawa T. Detection of dexmedetomidine in human breast milk using liquid chromatography-tandem mass spectrometry: Application to a study of drug safety in breastfeeding after Cesarean section. J Chromatogr B Analyt Technol Biomed Life Sci. 2017;1040:208-213.

27. Mahmoud M, Mason KP. Dexmedetomidine: review, update, and future considerations of paediatric perioperative and periprocedural applications and limitations. $\mathrm{Br} \mathrm{J}$ Anaesth. 2015;115:171-182.

28. Lo YL, Lin TY, Fang YF, Wang TY, Chen HC, Chou CL, Chung FT, Kuo CH, Feng PH, Liu CY, Kuo HP. Feasibility of bispectral index-guided propofol infusion for flexible bronchoscopy sedation: a randomized controlled trial. PLoS One. 2011;6:e27769.

29. Conway A, Douglas C, Sutherland JR. A systematic review of capnography for sedation. Anaesthesia. 2016;71:450-454.

30. Nassar BS, Schmidt GA. Capnography During Critical Illness. Chest. 2016;149:576-585.

31. Cook-Sather SD, Harris KA, Chiavacci R, Gallagher PR, Schreiner MS. A liberalized fasting guideline for formulafed infants does not increase average gastric fluid volume before elective surgery. Anesth Analg. 2003;96:965-969.

32. Goneppanavar U, Magazine R, Periyadka Janardhana B, Krishna Achar S. Intravenous Dexmedetomidine Provides Superior Patient Comfort and Tolerance Compared to IntravenousMidazolam in Patients Undergoing Flexible Bronchoscopy. Pulm Med. 2015;2015:727530.

33. Mason KP, Robinson F, Fontaine P, Prescilla R. Dexmedetomidine offers an option for safe and effective sedation for nuclear medicine imaging in children. Radiology. 2013;267:911-917.

34. Malik JA, Gupta D, Agarwal AN, Jindal SK. Anticholinergic premedication for flexible bronchoscopy: a randomized, double-blind, placebo-controlled study of atropine and glycopyrrolate. Chest. 2009;136:347-354.

35. Simon M, Braune S, Frings D, Wiontzek AK, Klose H, Kluge S. High-flow nasal cannula oxygen versus noninvasive ventilation in patients with acute hypoxaemic respiratory failure undergoing flexible bronchoscopy-a prospective randomised trial. Crit Care. 2014;18:712. 